\title{
Incidence of Phthiriasis palpebrarum caused by pubic lice Pthirus pubisin Al-Sulaimaniyah province, Kurdistan region, Iraq
}

\author{
Omer Mahmood Amin ${ }^{1^{*}}$ Nahla Mahmood Ameen ${ }^{2}$
}

${ }^{1} \mathrm{PhD}$ of Parasitology, Biology Depatment, College of Education, University of Garmian, Kalar, AlSulaimaniyah, Kurdistan Region, Iraq

${ }^{2}$ High Diploma of Ophthalmology,Shahid Doctor Aso Hospital, Department of Ophthalmology

Clinic, Al-Sulaimaniyah, Kurdistan Region, Iraq

Email: nahlajaf@gmail.com

*Corresponding author. Email: omer.mahmood@garmian.edu.krd

\begin{abstract}
Phthiriasis palpebrarum is a rare infection caused by pubic lice Pthirus pubis. This parasite has become a public health problem since itinfestshuman eyes and has been linked with other infections like keratitis, conjunctivitis and blepharitis. The present study was carried out on 2325 patients attended Doctor Shahid Aso Hospital in AlSulaimaniyah province, Kurdistan region, Iraq from January to November 2017. Four patients were observed to have symptoms like itching, redness, swollen of the eyelids with the presence of tiny white objects at the base of their eyelashes . Through examination using slit lamp and florescent microscopes, it was observed that the infections were caused by infestation with adults and nymphs of Pthirus pubis. Lice and nits were removed mechanically using fine forceps followed by treatment of the patients with erythromycin eye ointment. All the patients were treated successfully. To the best of our knowledge this is the first documentation of phthariasis papebrarum in Kurdistan and Iraq. Further studies are required for better understanding the ecology, phylogeny and the potential of disease transmission of the parasite.
\end{abstract}

Keywords: Phthiriasis palpebrarum, Pthirus pubis, Al-Sulaimaniyah, Iraq

\section{Introduction}

Pediculus are obligate ectoparasites feed on blood and skin of human, theybelong to the (Phylum Arthropoda)(Karabela et al., 2015).According to the area of infestation, Pediculus can be categorized into three species: Pediculus capitis which are usually found on the hairs of the head. Second, Pediculus corporis which resemble pediculus capitis, and usually infest the hair on the human body, particularly the abdomen 
andPediculus pubis or Pthirus pubis, found in the human pubic region at the base of pubic hair (Yoon et al. 2003, Dehghani et al, 2013).

Pthirus pubis isgeographically distributed worldwide and it is estimated of having the potential to infest 2-10\% of human populations (Anderson and Chaney, 2009). Pthirus pubis has a crab-shaped body and the adults are small around 2-2.5 $\mathrm{mm}$ in length and gray in color, having a complete life cycle: eggs, nymphs and adults (Badri and Hafsi, 2017). Pubic lice are typically transmitted through sexual contact. It is also possible to catch pubic lice by using blankets, towels, sheets, or clothing of people who have pubic lice (Castaneda et al., 2000). The parasite can also transmit to the areas of human eyelashes and eyelids causing a disease called phthiriasis palpebrarum (Ashraf et al., 2014).

The most obvious symptoms of phthiriasis palpebrarumare itchiness of the eyelid margin, eye redness, Tearing, Feeling ill or tired, low-grade fever, small red spots at the bite sites and in some cases conjunctivitis (Wu et al., 2016). The parasites are removed from the eyelashes mechanically using forceps. However, in some heavily infested patients, it could be painful, so local treatment with creams or ointment are required (Burkhart et al., 2000; Karabela et al., 2015).Pediculus lice particularly head lice and body lice are well studied in Iraq and neighboring countries (Mahmood, 2010; Dehghani et al., 2013; Abdulla, 2015; Al-Marjan et al., 2015; Gharsan et el., 2016; Khidhir et al., 2017).However, no studies have been carried outbefore onan infestation of human eyes by Pthirus pubis(Phthiriasis palpebrarum) in Iraq particularly in Kurdistan region. This study aims to diagnose and treatphthiriasis palpebrarum among people attendingDoctor Shahid Aso hospital in Al-Sulaimaniyah province.

\section{Materials and Methods}

Thisstudy was conducted on 2325patients attended Ophthalmology department in Doctor Shahid Aso hospital from January to November2017. Slit lamp microscope, magnifying lenses were used for clinical diagnosis and fineforcepswere used for mechanical removal of the lice and nits.The Parasites were morphologically identified (based on outer morphology, shape of the claws, size and color of the parasite) using florescent microscope in the laboratories of Garmian University depending on identification key (Pratt and Litting., 1973).Patients were treated with erythromycin eye ointment for 5 days once a day to prevent bacterial conjunctivitis. The patients were examinedfor any unremoved lice infestationseven daysafter the first removal to ensure the complete removal of the parasites and were followed up for 30 days afterwards. 


\section{Results:}

The primary results using eye slit microscope indicated the presence of variously sized lice infesting the eyes of four patients. They were two children, a boy aged five years and a girl aged seven years and two adult females aged 35 and 46 years respectively. Itching and redness of the eyelid were observed in the infested patients, two of the patients had the experience of swollen eyelid. Further investigation using high resolution florescent microscope revealed that they were infested with Pthirus pubis(Figure 1).All the stages of the parasite (Eggs, Nymphs and adults) were observed in the infested patients. Some of the parasites were observed on the surface of the skin at the bases of the eyelashes and others were partially embedded in the eyelid of the eyes while others were almost completely penetrating the skin.

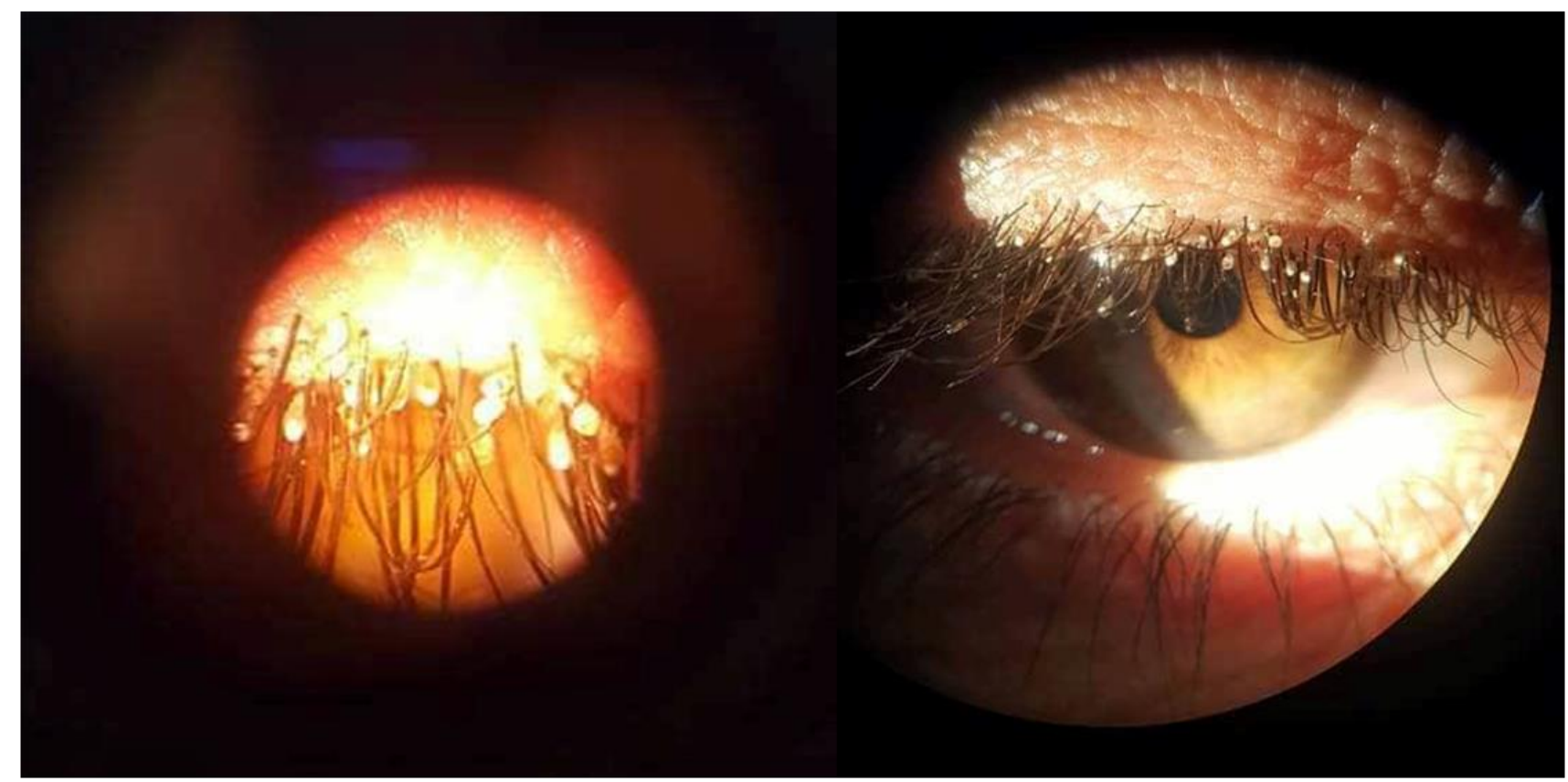

Figure (1): Pthirus pubis infesting eyes of a patient examined with slit lamp microscope

The size of the adults was about $2 \mathrm{~mm}$. the parasites transparent bodies were observed red due to the blood they had ingested from the host. No wings were observed. Male and female were hard to distinguish.

Nymphs had dark grayish color, morphologically and structurally exactly resembled the shape of the adults apart from their smaller size $1-1.5 \mathrm{~mm}$.

Microscopic examinations showed that eggs had a translucent yellowish brown color about the size of $0.5 \mathrm{~mm}$ attached to the eyelashes. Eggs were observed on three of 
the infested patients (75\%). Eggs had oval shapes and the larvae seemingly appeared inside and were covered with an outer egg shells.

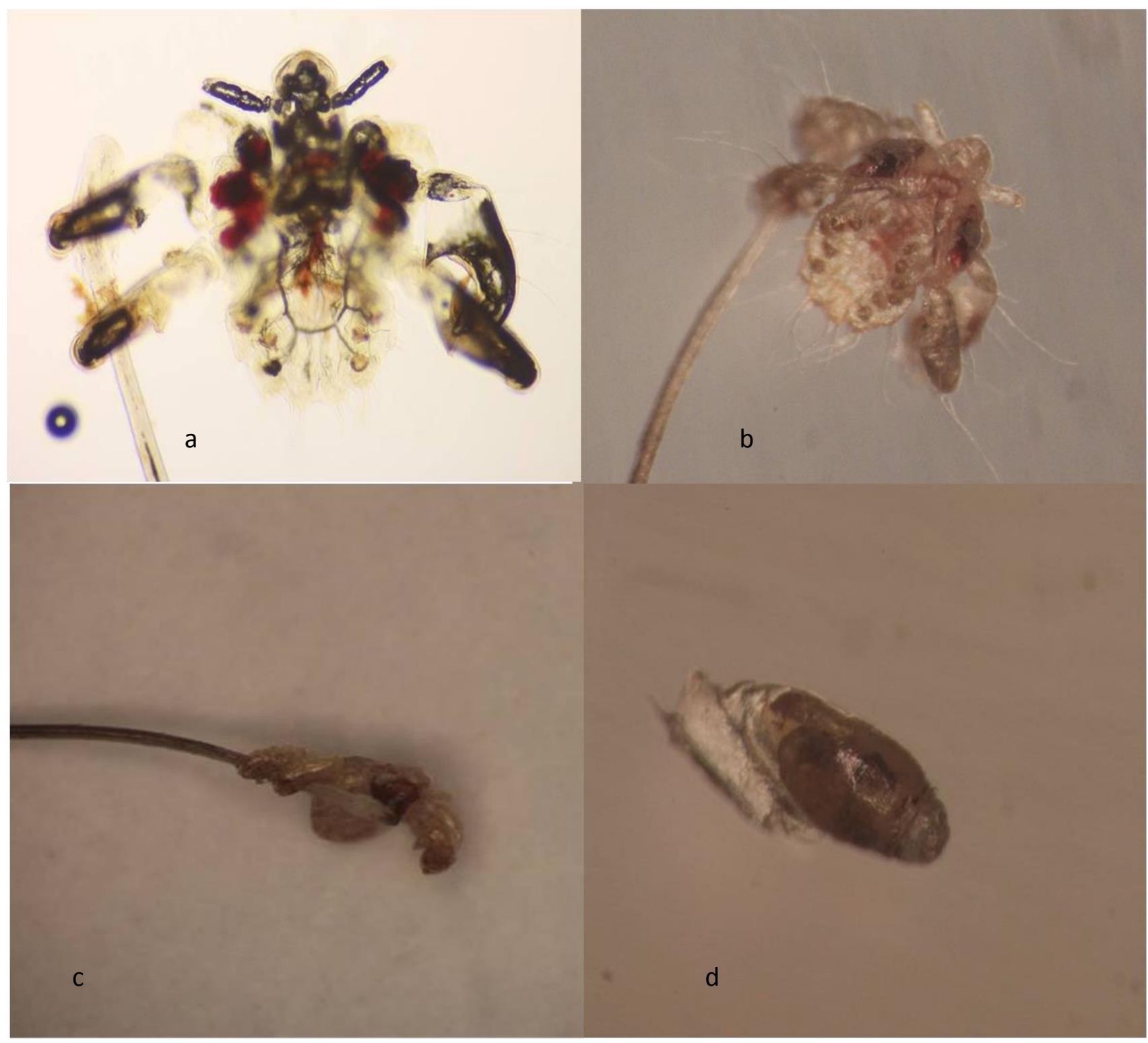

Figure (2): Microscopic views of Different stages of Pthirus pubis extracted from patients eyelashes. a and b represent adult lice $25 \mathrm{X}$, c represents nymph $30 \mathrm{X}$, and $\mathrm{d}$ represents egg 50 $\mathbf{X}$.

In the next clinical examinations under slit lamp microscope after seven days of the first mechanical removal of the parasites and antibiotictreatments, no parasites were observed in the infested eyes.Continuous checkupof the patients for up to 30 days confirmed the complete disappearing of lice after the mechanical treatment.

\section{Discussion:}

Phthiriasis palpebrarum is a rare infection caused by the parasitic lice Phthirus pubis (Ashraf et al., 2014). The parasite usually infests adults and reproducein the pubic 
hair because of their main mode of transmission during sexual contact (Yi et al., 2014). The parasites transmitviacontaminated handswith infested pubic hair to the eye area (Castaneda et al., 2000). Studies have shown that children can also be infested with the parasite (Yoon et al., 2003). Since children lack body hair and are immature for sexual practice, the parasite if present are always seen on the eyelashes. There is a potential of child abuse if the parasitesare diagnosed in children especially if their parents are not infested. In the current study the parasites were observed in both children and adults, it is believed that people in Kurdistan particularly the rural areas havecrowded families live together and in more cases share the same beds with their parents. Cases of Phthiriasis palpebrarum have been reported in countries that have borders with Kurdistan such as Iran and Turkey (Dehghani et al, 2013; Karabela, et al., 2015; Sundu et al., 2015). However, in the records we could not find any studied cases in Kurdistan or Iraq. Studies have shown that travelers could transmit the parasite from one place to another (Diaz, 2006). One of the adult patients in the present study had been recently returned from Iran prior to diagnosis. It is possible that she might caught the parasite from infested people in Iran and then carried them back to Kurdistan. Low hygiene, education level and socioeconomicstatus have also been linked to the availability of lice (Mahmood, 2010). Successful treatments of phthiriasis palpebrarum have been achieved using different mechanisms and medications including petroleum Jelly, permethrin, yellow mercuricoxide, vaseline, and recently argon laser (Couch etal., 1982; Jiang et al.,2011; Panos et al., 2013; Karabela, et al., 2015; Sundu et al., 2015). In the current study, a special fine forceps was used followed by erythromycin eye ointment and it was successful in eradication of the parasites from the eyes. Head and body lice are difficult to distinguish however pubic lice are different having broad stout legs especially the posterior two pairs and equipped with powerful claws with a round body. In this study, the use of florescent microscope facilitated easy characterization of the external morphology of the parasite.

In conclusion, Pthirus pubis can infest human in any country, this is the first study of phthriasis palpebrarum to be documented in Kurdistan and Iraq. Despite the parasites common occurrence in adults, children can also be infested. Mechanical removal of the parasites using fine forceps followed with 30 days follow up can successfully treat patients infected with lice infestation in the eyes. Travelling abroad and low socio economic status could increase the chance of catching the parasite. 


\section{References}

Abdulla, B.S. (2015). Morphological study and Prevalence of head lice (Pediculus humanus capitis) (Anoplura: Pediculidae) infestation among some primary school students in Erbil City, Kurdistan region. Zanko J applied Science. 27(5), 29-36.

Al-Marjan, K.S., Koyee,Q.M.K., and Abdulla, S.M. (2015). In Vitro Study On The Morphological Development Of Eggs (Nits) And Other Stages Of Head Lice Pediculus humanus capitis De Geer, 1767. Zanko J applied Science. 27(3), 35-40.

Anderson, A.L., and Chaney, E. (2009). Pubic lice (Pthirus pubis): history, biology and treatment vs. knowledge and beliefs of US college students. Int J Environ Res Public Health. 6(2), 592-600.

Ashraf, M., Waris,A., Kumar,A., and Akhtar, N. (2014). A case of unilateral phthiriasis palpebrarum infestation involving the left eye. BMJ Case Rep. 6, 1-3.

Badri, T., and Hafsi, W. (2017). Phthiriasis Palpebrarum. StatPearls [Internet]. Treasure Island (FL): StatPearls Publishing; 2017 Jun-. Available from http://www.ncbi.nlm.nih.gov/books/NBK459226/ PubMed PMID: 29083779.

Burkhart, C.N., Burkhart,C.G., MSPH., and Sylvania, M.D. (2000). Oral Ivermectin therapy for phthiriasis palpebrarum. Arch Ophthalmol. 51, 1037

Castaneda, A.N., Osorio,R.C., Pomar,J.L., Canales,J.L., and Salas, S.M. (2000). Phthiriasis Palpebrarum. Rev Fac Med UNAM. 43(5), 180-184.

Couch, J.M., Green,W.R., Hirst,L.W., and de la Cruz, Z.C. (1982). Diagnosing and treating Phthirus pubis palpebrarum. Surv Ophthalmol. 26(4), 219-225.

Dehghani, R., Limoee,M., and Ahaki, A.R. (2013). First report of family infestation with pubic louse (Pthirus pubis; Insecta: Anoplura: Pthiridae) in Iran--a case report. Trop Biomed. 30(1),152-154.

Diaz J.H. (2006). The epidemiology, diagnosis, management, and prevention of ectoparasitic diseases in travelers. J Travel Med. 13(2),100-111.

Gharsan F.N., Abdel-Hamed,N.F., Elhassan S.A., and Gubara, N.G. (2016). The prevalence of infection with head lice Pediculus humanus capitis among elementary girl students in Albaha region- Kingdom of Saudi Arabia. Int J Res Dermatol. 2(1), 12-17. 
Jiang J., Shen,T., and Hong, C.Y. (2011). A peculiar case of eye pruritus: phthiriasis palpebrarum initially misdiagnosed as common blepheritis. Int J Ophthalmol. 4(6), 676-577.

Karabela Y., Yardimci,G., Yildirim,I., Atalay,E., and Karabela, S.N. (2015). Treatment of Phthiriasis Palpebrarum and Crab Louse: Petrolatum Jelly and 1\% Permethrin Shampoo. Case Rep Med.; 2015:287906. doi: 10.1155/2015/287906. Epub 2015 Sep 15.

Khidhir, K.N., C.K. Mahmood and Ali W.K., (2017). Prevalence of infestation with head lice Pediculus humanus capitis (De Geer) in primary schoolchildren in the centre of Erbil city, Kurdistan region, Iraq. Pak. Ent. 39(2):1-4.

Mahmood S.A. (2010). Head pediculosis among in Baghdad area elementary schoolchildren. Iraqi J science. 1(51), 49-55.

Panos G.D., Petropoulos,I.K., D., and Gatzioufas, Z. (2013). Phthiriasis palpebrarum. BMJ Case Rep.; 2013. pii: bcr2013009272. doi: 10.1136/bcr-2013009272.

Pratt H.D and Litting K.S. (1973). Lice of public health importance. PP 23-26.

Sundu C., Dinc,E., Kurtulus,U.C., and Yildirim, O. (2015). Common blepheritis related to phthiriasis palpebrarum: Argon laser phototherapy. Turkiye Parazitol Derg. $39,252-254$.

Wu N., Zhang,H., and Sun, F.Y. (2017). Phthiriasis palpebrarum: A case of eyelash infestation with Pthirus pubis. Exp Ther Med. 13(2), 2000-2002.

Yi J.W., Li,L., and Luo da, W. (2014). Phthiriasis palpebrarum misdiagnosed as allergic blepharoconjunctivitis in a 6-year-old girl. Niger J Clin Pract. 17, 537-539.

Yoon K.C. Park,H.Y., Seo,M.S., and Park,Y.G. (2003). Mechanical treatment of phthiriasis palpebrarum. Korean J Ophthalmol. 17(1), 71-73. 